Check for updates

Cite this: J. Mater. Chem. B, 2021 9, 9012

Received 1st July 2021,

Accepted 1st October 2021

DOI: $10.1039 / d 1 t b 01463 c$

rsc.li/materials-b

\title{
Membrane protein channels equipped with a cleavable linker for inducing catalysis inside nanocompartments $\dagger$
}

\author{
Luisa Zartner, ${ }^{a}$ Viviana Maffeis, ${ }^{\text {ab }}$ Cora-Ann Schoenenberger, (D) ab \\ Ionel Adrian Dinu ${ }^{\mathrm{ab}}$ and Cornelia G. Palivan (D) *ab
}

\begin{abstract}
Precisely timed initiation of reactions and stability of the catalysts are fundamental in catalysis. We introduce here an efficient closing-opening method for nanocompartments that contain sensitive catalysts and so achieve a controlled and extended catalytic activity. We developed a chemistry-oriented approach for modifying a pore-forming membrane protein which allows for a stimuli-responsive pore opening within the membrane of polymeric nanocompartments. We synthesized a diol-containing linker that selectively binds to the pores, blocking them completely. In the presence of an external stimulus (periodate), the linker is cleaved allowing the diffusion of substrate through the pores to the nanocompartment interior where it sets off the in situ enzymatic reaction. Besides the precise initiation of catalytic activity by opening of the pores, oxidation by periodate guarantees the cleavage of the linker under mild conditions. Accordingly, this kind of responsive nanocompartment lends itself to harboring a large variety of sensitive catalysts such as proteins and enzymes.
\end{abstract}

\section{Introduction}

Different nanocompartments are specifically engineered to protect their cargo while supporting a triggered release of the cargo or other functionalities in response to an environmental stimulus. ${ }^{1-6}$ The nanocompartments enable cargo release by a change of their architecture upon a stimulus, while they preserve their integrity when the aim is to trigger an in situ reaction. ${ }^{7-10}$ Such stimuli-responsive nanocompartments have an increasing potential for applications ranging from catalysis to therapeutics. ${ }^{11,12}$ Catalytic activity and selectivity are also greatly enhanced by confining catalytic sites in specific compartments. ${ }^{13}$ Moreover, there is a strong interest in the field of nanomedicine and other biological applications for the development of photoredox-active catalyst systems that can be operated in pure water. The ability to perform chemical reactions in aqueous media together with effective recycling strategies for catalysts represent keystones for sustainable and green chemistry. Polymer-derived nanocompartments, in particular polymersomes that support triggered reactions inside, are changing their bounding membrane upon the

\footnotetext{
${ }^{a}$ Department of Chemistry, University of Basel, BPR1096, Mattenstrasse 24a, 4058 Basel, Switzerland. E-mail: cornelia.palivan@unibas.ch

${ }^{b}$ NCCR-Molecular Systems Engineering, BPR1095, Mattenstrasse 24a, 4058 Basel, Switzerland

$\dagger$ Electronic supplementary information (ESI) available. See DOI: 10.1039/ d1tb01463c
}

presence of a stimulus in their environment while preserving the architecture: the increased permeability favours the molecular flow across the compartment membrane, which will trigger an in situ functionality, for example by starting a specific reaction of the encapsulated active compounds. One strategy to generate stimuli-responsive polymersomes is to take advantage of stimuli-responsive copolymers to form nanocompartments that shrink or swell upon an external signal, e.g., $\mathrm{pH},{ }^{14} \mathrm{CO}_{2}{ }^{15,16}$ or a change in temperature. ${ }^{17,18}$ For example, polymersomes self-assembled from copolymers with tertiary, protonable amine groups show reversible swelling properties (breathing membrane) at distinct pH-values. ${ }^{14}$ Such $\mathrm{pH}$-sensitive copolymers include e.g. poly[2-(diethylamino)ethyl methacrylate] (PDEAEMA), poly(2-[dimethylamino)ethyl methacrylate] (PDMAEMA), or poly[( $N$-amidino)dodecyl acrylamide] (PAD) as protonable blocks. ${ }^{14,19}$ Other polymers forming $\mathrm{pH}$-responsive polymersomes are comprising polyacrylic acid (PAA) ${ }^{20,21}$ and poly(styrene sulfonate) (PSS). ${ }^{22}$ Another strategy, "bioinspired" by cellular membranes where numerous proteins mediate molecular transport across the membrane, hinges on incorporating proteins or small polypeptides into the polymersome membrane to achieve a desired permeability. ${ }^{23}$ For example, channel forming proteins such as the outer membrane protein $\mathrm{F}(\mathrm{OmpF})$, enable the diffusion of molecules with a cut-off largely corresponding to the pore diameter, ${ }^{24,25}$ while others, such as Ferrichrome outer membrane transporter (FhuA) or gramicidin, only allow diffusion of certain small molecules or ions. ${ }^{26,27} \mathrm{~A}$ step further in developing stimuli-responsive membrane permeabilization of 
polymersomes was achieved by turning inserted membrane proteins into "bio-valves" or "bio-locks" by corresponding modifications of the protein. For example, a pH-sensitive Gala3 peptide covalently bound to OmpF transformed the pores in the membrane of polymersomes into $\mathrm{pH}$-triggerable valves that regulate the molecular flow to and from the compartment. ${ }^{28}$ In the random coil conformation $(\mathrm{pH} 7.4)$, Gala3 appeared not to perturb passage through the pore, while upon protonation (pH 5.5), peptides assume an $\alpha$-helical structure that closed the pore, albeit only partially. Alternatively, permeability in response to a reducing environment was achieved in polymer-based artificial organelles by coupling a small molecular cap to cysteine residues of an OmpF double mutant: under reducing conditions, the cap was removed and the pores re-opened. ${ }^{29}$ Furthermore, polymersomes equipped with stimuli-responsive OmpF that encapsulate enzymes in their aqueous cavity served as catalytic nanocompartments (CNCs) whose activity was sensitive to open gates through which substrates could freely diffuse. ${ }^{28,29}$ Here we enlarge the concept of nanocompartments with stimuli-responsive in situ catalysis by developing a chemistry-based strategy for regulating substrate entry to the compartment. We rationally designed and synthesized a periodate sensitive linker to covalently bind to amino acids K89C/R270C of a double mutant of OmpF under mild conditions, thereby blocking the channel. We chose OmpF as a model membrane protein because it is a well characterized porin in terms of structural and functional characteristics. ${ }^{30}$ The linker was designed to crosslink two opposing cysteines located near the pore opening, and to be cleavable by periodate, an important oxidant for the selective oxidation of polysaccharides and glycopeptides. $^{31,32}$ The advantages of periodate lie in its specificity, stability, and reactivity under neutral and mild conditions, and even more so in its compatibility with the preparation of a plethora of bioactive natural products and fine chemicals. ${ }^{33-36}$ Conditions used for the cleavage by periodate usually do not significantly perturb the structure of proteins ${ }^{37,38}$ although side reactions such as the cleavage of glycans, methionines, cysteines or the oxidation of N-terminal threonine and serine moieties may occur. In addition, there are different examples of enzymes with periodate tolerance, such as hydrolases ${ }^{39-41}$ or proteases. ${ }^{37,38}$ Considering the results published by several groups on chemical proteomics that reveal an efficient and selective cleavage of periodate-sensitive 1,2-diol linkers, ${ }^{37,38,42}$ we chose periodate for the oxidative cleavage of the 1,2-diol derived $\mathrm{C}-\mathrm{C}$ bond in our linker because it presumably will not perturb OmpF function. 1,2-Diols are known to be oxidatively cleaved by sodium periodate via a cyclic transition state, in analogy with the oxidation by lead tetraacetate. The oxidation yields two carbonyl fragments, in this case two formylcontaining compounds. ${ }^{43}$ Besides, we were interested in synthesizing a water-soluble linker to enable applications without the use of organic solvents that are expected to harm membrane proteins.

\section{Results and discussion}

OmpF monomer has the structure of a hollow beta barrel embedded in the membrane, with a diameter of around $30 \AA$
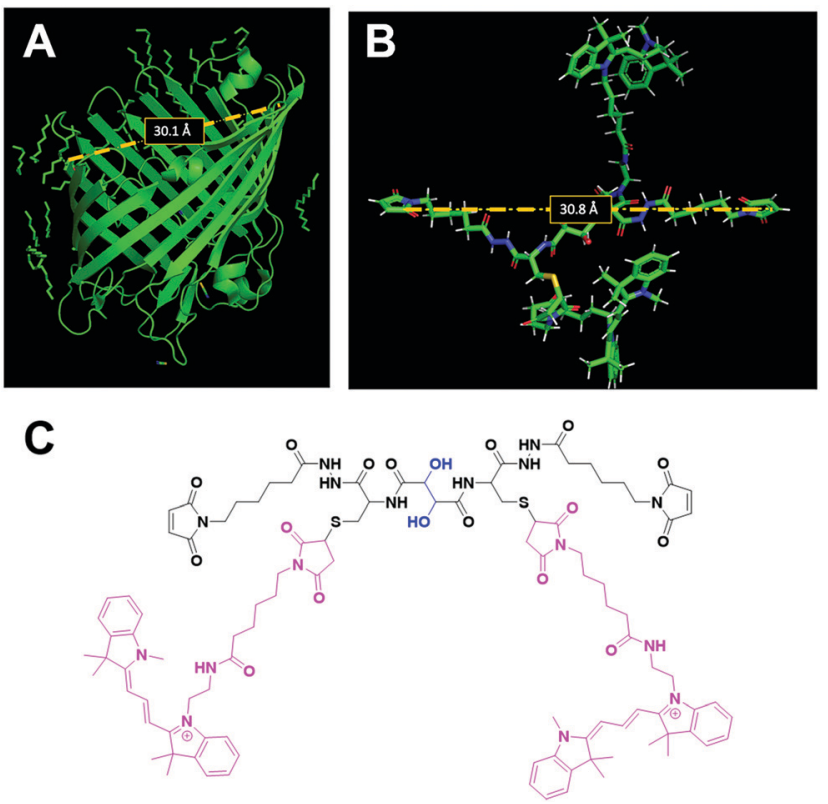

Fig. 1 OmpF structure and linker design. (A) PyMol ribbon representation of OmpF-M secondary structure reveals a distance of about $30 \AA$ between the side groups of the two amino acids replaced by Cys in OmpF-M. (B) The linker length corresponds to the distance between the two opposing Cys of OmpF-M, as estimated by PyMol modeling. (C) Chemical structure of the designed linker terminal maleimide groups, fluorophore side chains (pink) and the diol unit (blue).

(Fig. 1A), enabling diffusion of small (generally under $600 \mathrm{Da}$ ) water-soluble molecules ${ }^{16}$ in both directions. To achieve the chemical modification necessary to bind the linker, we used OmpF-M, a genetically modified porin that features two cysteine (Cys) residues opposing each other in the 'eyelet' region of the pore (OmpF double mutant K89C/R270C, OmpF-M) ${ }^{20}$ The thiol groups of these Cys moieties are exposed and can be readily modified (Fig. 1). To block OmpF pores by covalent binding of an organic compound and induce a controlled opening by periodate, different requirements have to be considered in terms of size and conformation of the linker, its accessibility and efficient cleavage. First, the steric size and conformation of the linker should efficiently block the pore, and second, both ends of the linker should be bound to OmpF to minimize the freedom of rotation. Thus, we opted to synthesize a small organic compound to provide a more rigid structure compared to coiled macromolecules where the spatial orientation and folding is more difficult to predict. ${ }^{44,45}$ Furthermore, the length of the linker was designed to span the diameter of the OmpF-M pore at the site of the two Cys moieties, i.e. approximately $30 \AA$, whereas a maleimide group at each linker end was inserted to favor the reaction with the thiol side chains of the two cysteines (Fig. 1C). ${ }^{46}$ Third, an important factor to consider in the linker design was the periodate-responsiveness that would result in its oxidative cleavage to unblock of the OmpF 'gate'. Hence, we introduced a vicinal diol unit with a periodate-sensitive $\mathrm{C}-\mathrm{C}$ bond in the middle of the symmetric linker (Fig. 1C, in blue). Periodate oxidizes the diol into the corresponding carbonyl groups under mild conditions, at $\mathrm{pH}=7$ and room 
temperature. ${ }^{25}$ Oxidation by periodate is predicted to produce two fragments able to rotate freely as they are bound only at one end to a Cys side chain. Hence, we anticipate that the periodatetriggered cleavage of the linker releases the OmpF pore obstruction. Finally, our linker design included two fluorophore (cyanine3 dye) side chains, both to create a bulkier structure for a more efficient pore blocking and to allow detection by fluorescence-based techniques. Synthesis of the periodateresponsive linker was performed in three consecutive steps (Scheme 1). We started from the vicinal diol element of a disuccinimidyl derivative of tartaric acid and symmetrically built up the linker on both sides. To achieve a final linker length of approximately $30 \AA$ A, we coupled two cysteine molecules to the respective ends of the reactive ester, to which we then covalently
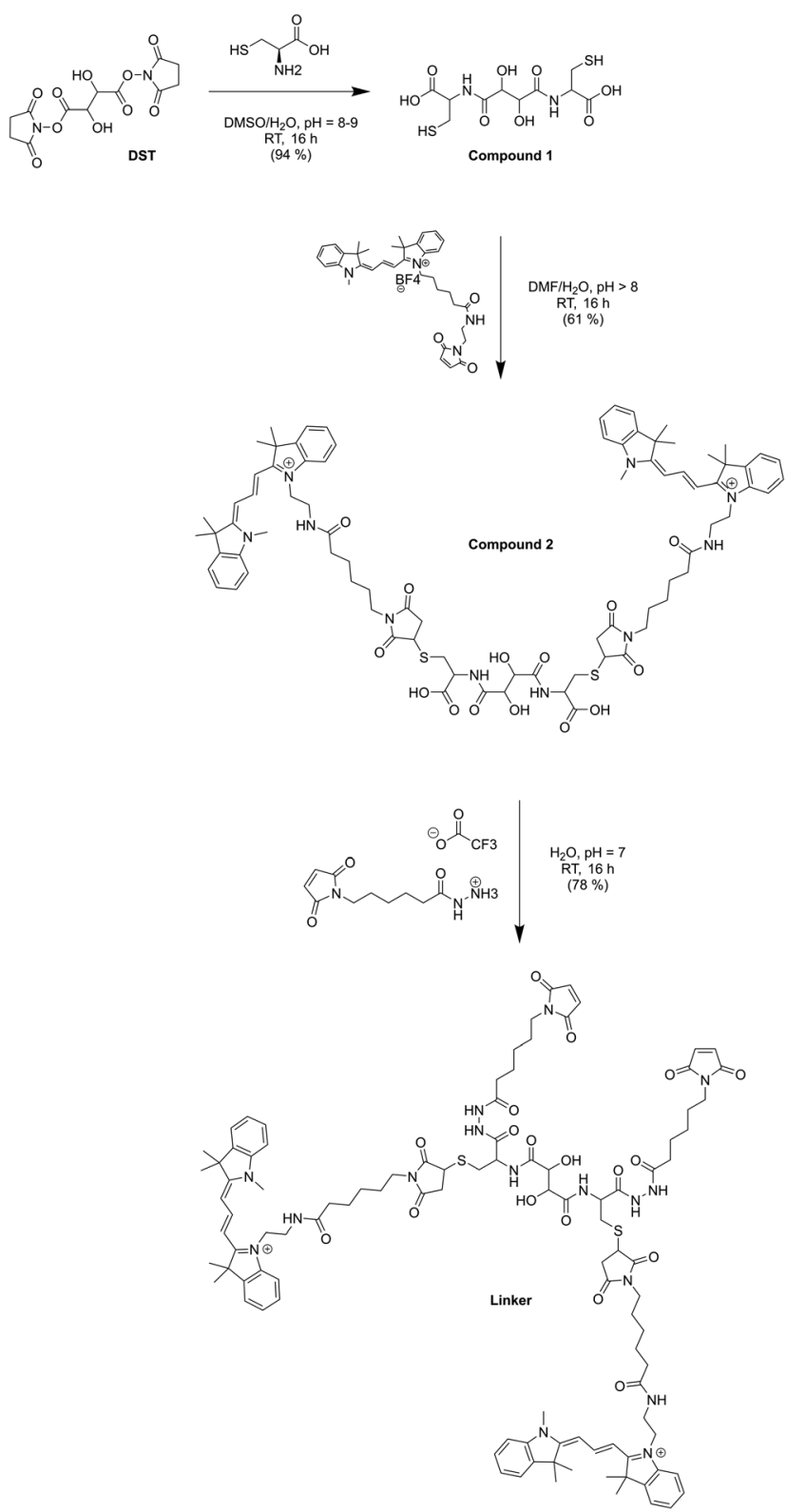

Scheme 1 Chemical synthesis of the periodate-responsive, fluorescent linker. attached cyanine 3 maleimides as fluorescent side chains via the thiol groups. The two functional maleimide end groups of the linker were integrated using a compound combining maleimide with a small hydrocarbon chain and hydrazide as the second end functional group. The hydrazide moiety reacted selectively with the carboxylate group of the cysteine fragments resulting in the final linker with a length of $30 \AA$ (Fig. 1B).

In the first step, cysteine was coupled with disuccinimidyl tartrate (DST; a crosslinker with known periodate oxidationinduced cleavage properties) ${ }^{47}$ by the simple reaction of amine groups with the NHS-activated tartaric acid (Scheme 1). We assumed periodate to be the best choice of oxidant to selectively cleave the diol bond of the final linker as it reacts under mild conditions (i.e., no organic solvents or harsh additional substrates like acid or bleach required, but aqueous solutions, neutral $\mathrm{pH}$, ambient temperature). Because oxidation of hydrazide bonds requires harsh conditions, we presume it unlikely that oxidative cleavage of the hydrazide groups occurs in our experimental system. In addition, compared to other oxidants, periodate is by itself a mild oxidant that presumably would not damage the sensitive structure of OmpF. This step was necessary to introduce the reactive thiol groups which were subsequently needed for coupling the fluorescent cyanine3 maleimide molecules. The first intermediate (compound 1) was only partially purified prior to being used for the synthesis of compound 2 . The ${ }^{1} \mathrm{H}$-NMR spectrum of compound 1 showed the characteristic peaks of the coupled cysteine found in the range of 3.45-3.30 ppm and $4.65 \mathrm{ppm}$ corresponding to the methylene $\left(\mathrm{CH}_{2}-\mathrm{SH}\right)$ and methine $(\mathrm{NH}-\mathrm{CH})$ groups, together with the two protons $(\mathrm{CH}-\mathrm{CH})$ of the vicinal diol unit at 4.7$4.6 \mathrm{pm}$. Additionally, the spectrum indicated the presence of monofunctional product, cysteine and free $N$-hydroxy succinimide. The ${ }^{13} \mathrm{C}-\mathrm{NMR}$ spectrum confirmed the presence of carbons around 180-170 ppm characteristic for carbonyl moieties from amides and carboxylic acids, the two carbons of the vicinal diol unit around $70 \mathrm{ppm}$, and the two carbon atoms of the cysteine connected to the tartaric acid by amide groups at around $50 \mathrm{ppm}$. Analysis by ESI-MS revealed a value of $\mathrm{m} / \mathrm{z}=$ 179.05, which corresponds to double the protonated compound $\mathbf{1}[\mathrm{M}+2 \mathrm{H}]^{+}$and could not be assigned to DST or cysteine. Compound 1 was used in the second reaction step aiming to induce its selective reaction with cyanine 3 maleimide, resulting in compound 2 . The ${ }^{1} \mathrm{H}-\mathrm{NMR}$ spectrum of compound 2 showed that possible impurities resulting from the synthesis of the first intermediate were efficiently removed during the purification step and did not lead to any other side products nor disrupt the reaction affording compound 2 (Fig. S1, ESI $\dagger$ ). In addition to the protons of the vicinal diol element of tartaric acid and the cysteine fragments, we observed peaks in the 9.00-5.50 ppm range, characteristic for the heterocyclic and aromatic rings, as well as for the extended conjugation of the double bonds of the cyanine3 dye. The singlet peak characteristic for the two protons of the maleimide groups was not identified in the spectrum, indicating the complete coupling of cyanine3 maleimide and consequently the formation of compound 2 . According to the ${ }^{13} \mathrm{C}-\mathrm{NMR}$ spectrum, the characteristic peaks of 
the carbon atoms from the carboxylic acids and amides were visible in the 180-170 ppm range. In addition, carbon peaks of cyanine3 dye were observed, including a peak at $168 \mathrm{ppm}$ representing carboxamides, $\mathrm{C}=\mathrm{C}$ groups around $140 \mathrm{ppm}$, aromatic carbons around 120-110 ppm, aliphatic amines between 50-30 ppm, and the hydrocarbon chains in the 30-20 ppm range (Fig. S2, ESI $\dagger$ ). Analysis of the product by MS (MALDI-TOF) revealed an $m / z$ value of $[\mathrm{M}+2 \mathrm{H}]^{+}=379.16$, corresponding exactly to compound 2 . In the last synthesis step, the carboxylic acid groups of compound 2 were activated by EDC to form the amine-reactive $O$-acyl isourea intermediate. Subsequently, the reaction with $N$ - $\varepsilon$-maleimidocaproic acid hydrazide (EMCH) led to the formation of a symmetric bismaleimide linker, as confirmed by the NMR spectra (Fig. S3 and S4, ESI $\dagger$ ). In addition to the peaks that were already observed for compound 2 , the ${ }^{1} \mathrm{H}$-NMR spectrum showed peaks between 2.0-1.0 ppm, characteristic for protons of the two hydrocarbon chains that were introduced by reacting compound 2 with EMCH. The hydrazide group of the crosslinker EMCH commonly generates a very broad peak between 4.5$3.5 \mathrm{ppm}$ with an integral of 4 , which was not found in the ${ }^{1} \mathrm{H}$-NMR spectrum of our final product. The ${ }^{13} \mathrm{C}$-NMR spectrum of the final linker indicated its large hydrocarbon backbone and showed the characteristic peaks of the two carboxamines carbons from the coupled maleimide groups around $165 \mathrm{ppm}$. Interestingly, the peaks of the aromatic carbons from the fluorophore were no longer detected. However, we concluded that this absence represents an effect of a decreased solubility in $\mathrm{CDCl}_{3}$ when the linker was dissolved in the NMR-tube (Fig. S4, ESI $\dagger$ ). Additionally, MALDI-TOF revealed an $\mathrm{m} / \mathrm{z}$ value of $[\mathrm{M}+\mathrm{H}]^{+}=643.68$, which corresponds exactly to the bismaleimide linker.

Next, we mixed the bifunctional linker with purified recombinant OmpF-M in water to couple the maleimide groups of the linker to the thiol groups of the Cys residues in OmpF and close the OmpF pore. After the labeling reaction, an aliquot of the linker-OmpF-M solution was heated to $95{ }^{\circ} \mathrm{C}$ to denature all intramolecular interactions except covalent bonds, and then analyzed by SDS-PAGE (Fig. S5, ESI $\dagger$ ). We observed a single fluorescent band running with the apparent molecular weight of monomeric OmpF-M (about $40 \mathrm{kDa},{ }^{48}$ lanes 3, 4), which indicated a covalent binding of the fluorescent linker to the OmpF-M. As unspecific aggregation of the linker with the protein was not apparent, we concluded that covalent binding was successful.

We were interested to establish whether the linker attachment to the OmpF-M was able to (i) efficiently close the pore and (ii) control the molecular flow through the OmpF pore in a precise manner. Hence, we prepared several types of polymersomes encapsulating laccase in their aqueous cavity, henceforth termed catalytic nanocompartments (CNCs), as model for stimuli-responsive regulation of enzyme activity: (i) CNCs without OmpF-M pores (CNC-noOmpF-M), (ii) CNCs with inserted linker-modified OmpF-M (CNC-linker-OmpF-M), (iii) CNCs with inserted OmpF-M lacking the linker modification (CNC-OmpF-M), and (iv) CNCs with wild-type OmpF inserted in their membranes (CNC-OmpF-WT). We used the film rehydration method $^{49}$ to form polymersomes and CNCs from poly(2-methyl-2oxazoline)-block-poly(dimethyl-siloxane)-block-poly(2-methyl-2oxazo-line), $\mathrm{PMOXA}_{11}-b$-PDMS ${ }_{104}-b$-PMOXA 11 . Such amphiphilic triblock copolymers (PMOXA- $b$-PDMS- $b$-PMOXA) are known to self-assemble into polymersomes with membranes that are sufficiently flexible to integrate OmpF despite the hydrophobic mismatch. ${ }^{50,51}$ The average number of MOXA and DMS repeating units in PMOXA $_{11}-b$-PDMS ${ }_{104}-b$-PMOXA 11 was assessed by proton nuclear magnetic resonance $\left({ }^{1} \mathrm{H}-\mathrm{NMR}\right)$ spectroscopy (Fig. S6, $\mathrm{ESI} \dagger$ ). This method also allowed for obtaining the numberaverage molecular weight of this copolymer $\left(M_{\mathrm{n}}=9800 \mathrm{~g} \mathrm{~mol}^{-1}\right)$, whereas a dispersity $(D)$ of 1.23 was revealed by gel permeation chromatography (GPC) (Fig. S7, ESI $\dagger$ ). The size and architecture of CNCs were characterized by transmission electron microscopy (TEM), fluorescence correlation spectroscopy (FCS), and light scattering (LS) (Fig. 2 and Table 1). All three techniques indicated a hollow sphere architecture with a diameter of around $200 \mathrm{~nm}$ with appropriate homogeneity (polydispersity index, PDI $=0.2$ ).

TEM micrographs revealed $200 \mathrm{~nm}$ structures characteristic for collapsed vesicles (Fig. 2A-D). We used static (SLS) and dynamic light scattering (DLS) to obtain the radius of gyration $\left(R_{\mathrm{g}}\right)$ and radius of hydration $\left(R_{\mathrm{h}}\right)$ for all CNCs (Table 1$)$. CNC-linker-OmpF-M, CNC-OmpF-M and CNC-OmpF-WT were in a similar range of size with $R_{\mathrm{h}}$ of around $120 \mathrm{~nm}$ and $R_{\mathrm{g}}$ of 100-110 nm, while CNC-noOmpF were slightly bigger $\left(R_{\mathrm{h}}=138\right.$, $\left.R_{\mathrm{g}}=134 \mathrm{~nm}\right)$. The calculated ratios of $R_{\mathrm{h}} / R_{\mathrm{g}}$ ranged between 0.8-1.0, presenting typical values for hollow sphere architectures linker to OmpF-M was assessed by FCS (Fig. 2E). The autocorrelation curves revealed significant shifts in the diffusion time values of standalone linker-OmpF-M relative to free linker and linker-OmpF-M permeabilized CNCs relative to standalone linker-OmpF-M (Table S1, ESI $\dagger$ ). These characteristic increases in diffusion time values indicate a successful coupling of the linker to OmpF-M and a successful insertion of the linker-OmpF$\mathbf{M}$ in the membrane of polymersomes. In addition, we used brightness measurements to evaluate the number of linker molecules/OmpF pore. With the counts per molecules given in Table S1 (ESI $\dagger$ ), we calculated that one linker molecule is bound per OmpF-M monomer and obtained an average number of 9 reconstituted linker-OmpF-M molecules per CNC. We next assayed the activity of encapsulated laccase in CNCs after treatment with $\mathrm{NaIO}_{4}$, quenching with glucose and SEC purification. To determine laccase activity, we used 2,6-dimethoxyphenol (DMP; MW 154.16), a substrate that is small enough to diffuse through OmpF pores. Laccase catalyses the oxidation of DMP to the corresponding radical species. The resulting orange radical can be detected spectrophotometrically at $470 \mathrm{~nm} .^{52,53}$ As CNCs self-assembled from PMOXA-PDMS-PMOXA triblock copolymers show a characteristic absorption at $280 \mathrm{~nm},{ }^{54}$ and the fluorescent linker at $550 \mathrm{~nm}$, their interference with oxidized DMP (470 nm) could be largely excluded. The periodate-triggered unblocking of OmpF-M pores in CNCs was evaluated by measuring the absorbance related to DMP oxidation for several hours (Fig. 3). When DMP was added to CNC-linker-OmpF-M in the absence of $\mathrm{NaIO}_{4}$, where OmpF pores should be blocked, the 

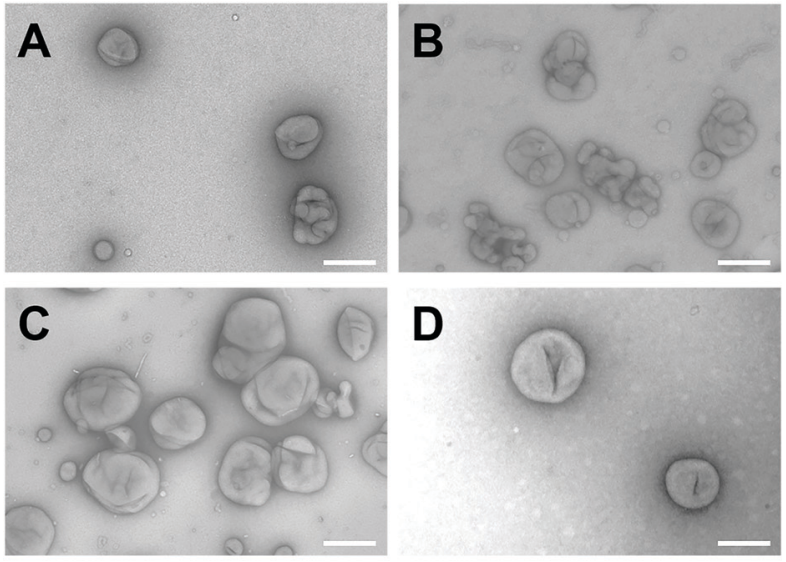

$\mathbf{E}$

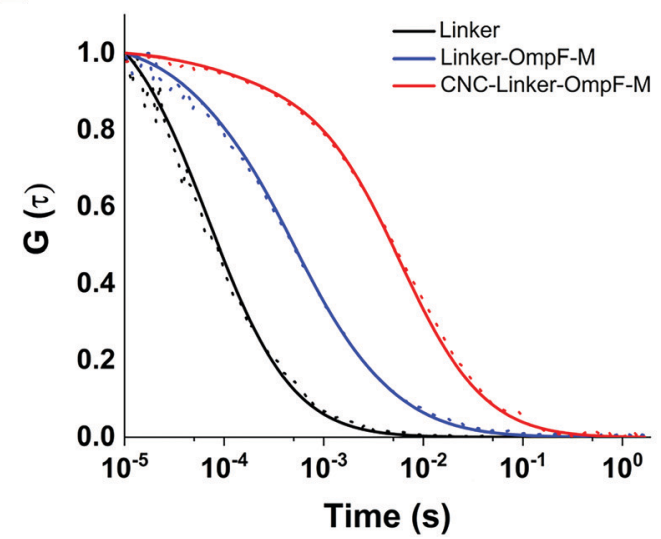

Fig. 2 Insertion of linker-modified OmpF-M in CNC membranes. Ultrastructural morphology of (A) CNCs without OmpF, (B) CNCs with linker-OmpF-M inserted in the membrane, (C) CNCs with OmpF-M, and (D) OmpF wild-type. Scale bars: $200 \mathrm{~nm}$. (E) FCS autocorrelation curves (solid line) and raw data (dots) of PBS solutions of the linker (black), standalone linker-OmpF-M in 1\% OG (blue), and CNCs with linkerOmpF-M inserted in the membrane (red).

Table 1 Shape and size determination of CNCs

CNC-linker-

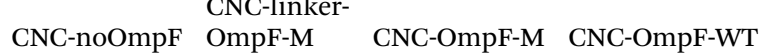

\begin{tabular}{lllll}
\hline PDI & 0.2 & 0.2 & 0.2 & 0.2 \\
$R_{\mathrm{h}}(\mathrm{nm})$ & 138 & 118 & 119 & 121 \\
$R_{\mathrm{g}}(\mathrm{nm})$ & 134 & 113 & 101 & 101 \\
Ratio & 1.0 & 0.9 & 0.8 & 0.8 \\
Plot & Guinier & MIE & MIE & Guinier
\end{tabular}

enzyme activity was similarly low as for CNCs lacking OmpF. This data confirms that the pores are blocked by the linker and thus the substrate is unable diffuse through the pores to reach the enzyme. $\mathrm{NaIO}_{4}$ treatment of CNC-linker-OmpF-M led to a significantly higher absorbance at $470 \mathrm{~nm}$ as cleavage of the linker unblocked the pores and DMP was able to diffuse into the cavity where it was oxidized to the coloured product (Fig. 3, green curve). Periodate treatment of CNC-noOmpF-M did not yield notable absorbance, indicating that $\mathrm{NaIO}_{4}$ by itself did not damage the CNCs (Fig. 3, red curve) which would have otherwise

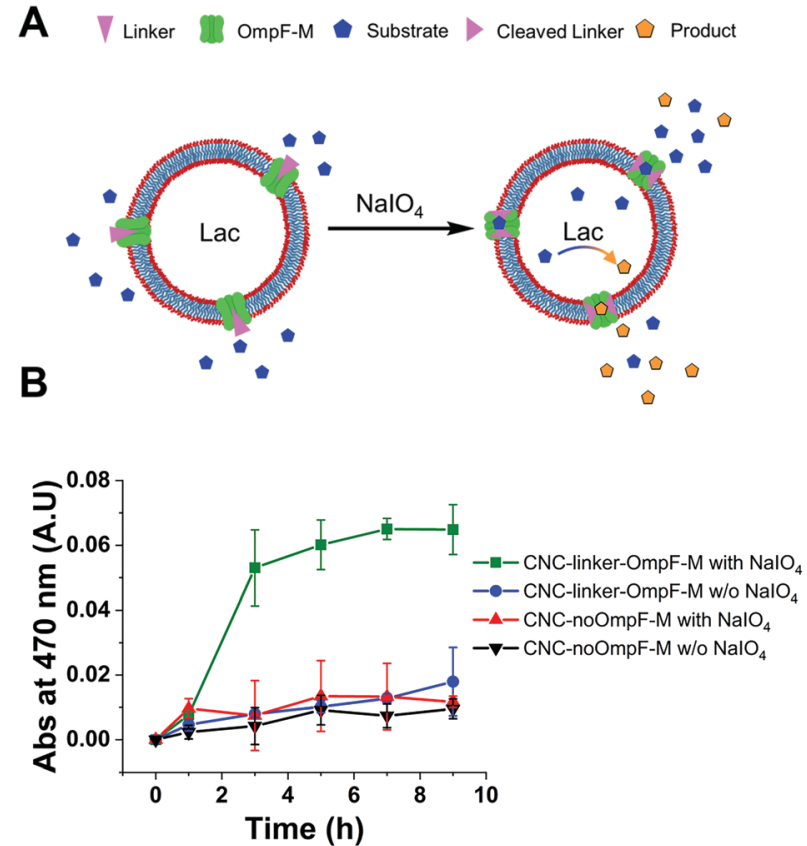

Fig. 3 Linker-based control of laccase activity in CNCs in response to $\mathrm{NaIO}_{4}$. (A) Schematic representation of periodate-induced linker cleavage, activating in situ catalysis. Addition of $\mathrm{NaIO}_{4}$ cleaves the linker and thereby unblocks the pore. In the open state, substrate enters the compartment where it is oxidized to a detectable product by the confined laccase. (B) An increase in absorbance at $470 \mathrm{~nm}$ reflects laccase-catalyzed DMP conversion in $\mathrm{NaIO}_{4}$-treated $\mathrm{CNC}$-linker-OmpF-M. Laccase activity was minimal in CNCs lacking OmpF or in CNC-linker OmpF-M in the absence of $\mathrm{NalO}_{4}$ (closed pores). Measurements were carried out at $\mathrm{pH} 7.4$ for 9 hours at RT.

led to a release of laccase and to an enzyme-catalysed oxidation of DMP. In all laccase activity assays, periodate treatment was followed by quenching with glucose to avoid false positive signals from periodate-induced oxidation reactions. Our spectrophotometric results clearly show that while the linker closes OmpF pores efficiently, a stimuli-responsive opening is achieved by periodate-triggered linker cleavage. Furthermore, the increased absorbance over several hours demonstrated that periodate did not affect the activity of encapsulated laccase.

To test how long triggered laccase activity persists when protected by the polymersome membrane, we measured DMP of free laccase reached a maximum after $8 \mathrm{~h}$ and then continuously decreased over the following $12 \mathrm{~h}$ (Fig. 4A). In contrast, enzymatic activity of CNCs whose membrane was permeable to DMP either by unmodified OmpF-M pores (CNCOmpF-M) or by periodate-induced opening of linker-OmpF-M pores (CNC-linker-OmpF-M), increased for seven days (Fig. 4B). Again, without OmpF pores in the membrane, $\mathrm{NaIO}_{4}$ treatment (CNC-no-OmpF with $\mathrm{NaIO}_{4}$ ) did not lead to the oxidation of DMP, nor did it affect CNC morphology, as shown by TEM micrographs (Fig. 4C-F). For comparison and to rule out that the increase in absorbance was related to an unspecific effect of $\mathrm{NaIO}_{4}$ on DMP, we also tested laccase activity of corresponding CNCs using 2,2'-azino-bis(3-ethylbenzothiazoline-6-sulfonic acid diammonium salt) (ABTS) as substrate (Fig. S8, ESI $\dagger$ ). 
A
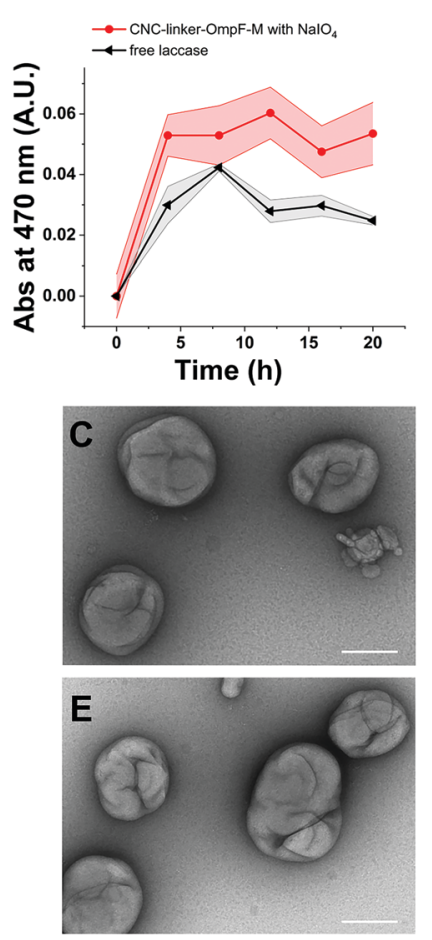

B
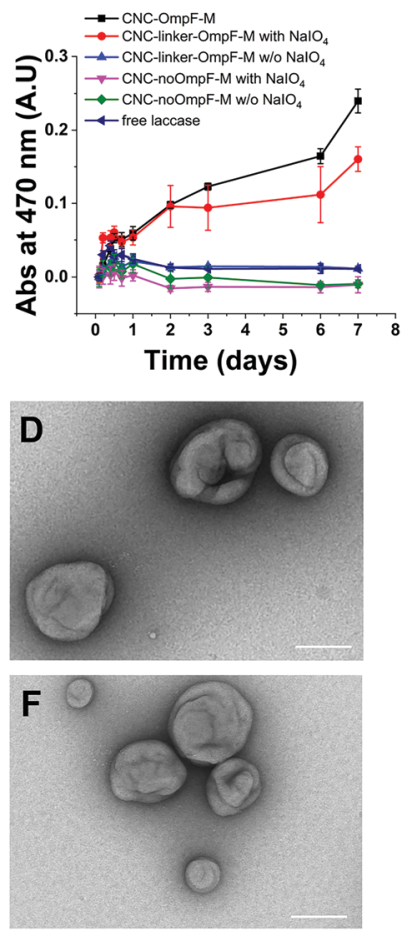

Fig. 4 Long-term laccase activity of CNCs in response to $\mathrm{NaIO}_{4}$ Absorbance intensity of the laccase product was measured at $470 \mathrm{~nm}$. Measurements were carried out in triplicate $( \pm S D)$ at $\mathrm{pH} 7.4$ and $\mathrm{RT}$. (A) Activity of free laccase in PBS compared to laccase encapsulated in $\mathrm{CNC}$-linker-OmpF in the presence of $\mathrm{NaIO}_{4}$ over $20 \mathrm{~h}$. (B) Activity measured for one week of free laccase in PBS compared to CNCs with and without periodate-cleaved pores or CNCs lacking pores. Periodate treatment had no effect on the ultrastructural morphology of (C) CNClinker-OmpF-M compared to (D) CNC-no OmpF after 1 week nor after 3 weeks ( $E$ and $F$, respectively). Scale bars: $200 \mathrm{~nm}$.

These enzyme assays were performed over several months, indicating that CNCs were active over long time periods if stored at $4{ }^{\circ} \mathrm{C}$. Because DMP exhibited notably lower autooxidation $^{42}$ over $9 \mathrm{~h}$ at $\mathrm{pH} 7.4$, it was more suitable for longterm measurements of $\mathrm{NaIO}_{4}$-induced CNC catalysis (Fig. 4). ABTS on the other hand, as non-phenolic substrate is reported to be a more efficient substrate under acidic conditions. ${ }^{55}$ Further evidence of the longevity of CNCs encapsulating laccase was provided by TEM micrographs after eleven months which revealed an unchanged morphology (Fig. 5). Long-term stability of CNCs represents a key aspect for future applications of this system.

\section{Materials and methods}

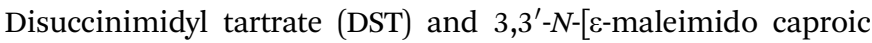
acid] hydrazide, trifluoroacetic acid salt (EMCH) were purchased from Thermo Fisher, cyanine3 maleimide from Lumiprobe. All other materials were purchased from Sigma Aldrich. All reagents were of the highest commercially available grade and were used without any further purification, unless stated otherwise.
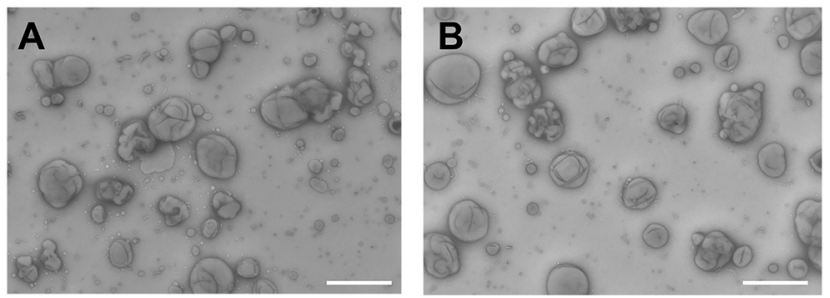

Fig. 5 Longevity of CNC morphology. TEM micrographs of CNCs encapsulating laccase with (A) unmodified OmpF-M inserted in the compartment membrane, and (B) linker-OmpF-M reveal an intact morphology after 11 months at $4{ }^{\circ} \mathrm{C}$. Scale bars: $500 \mathrm{~nm}$.

\section{Synthesis of amphiphilic triblock copolymer}

The amphiphilic block copolymer PMOXA $_{11}-b-\mathrm{PDMS}_{104}-b$ PMOXA $_{11}$ was previously synthesized in our group according to reported protocols. ${ }^{56,57}$ Briefly, a hydroxyl-terminated bifunctional PDMS was reacted below $-10{ }^{\circ} \mathrm{C}$ with trifluoromethanesulfonic anhydride in dry hexane, leading to the activated PDMS macroinitiator. After filtration under argon and removal of hexane under vacuum, dry chloroform was added as reaction solvent, in which dry 2-methyl-2-oxazoline (MOXA) reacted with the macroinitiator via symmetric cationic ring-opening polymerization. The hydroxyl-terminated triblock copolymer was obtained after quenching the polymerization reaction with a water/ethanol mixture. A number-average molecular weight $\left(M_{\mathrm{n}}\right)$ of $8700 \mathrm{~g} \mathrm{~mol}^{-1}$ and a chemical composition of $\mathrm{PMOXA}_{12}-b-\mathrm{PDMS}_{87}-b-\mathrm{PMOXA}_{12}$ was obtained from the ${ }^{1} \mathrm{H}-\mathrm{NMR}$ spectrum of this triblock copolymer, whereas its dispersity $(D)$ of 1.6 was revealed by gel permeation chromatography (GPC) in tetrahydrofuran (THF). ${ }^{57}$ To decrease the dispersity and thereby better control the shape morphology of the self-assembled structures, the copolymer was extracted with a $1: 1(\mathrm{v} / \mathrm{v})$ hexane/methanol mixture and the copolymer fraction with a longer PDMS block was recovered from the hexane phase after solvent removal and characterized by ${ }^{1} \mathrm{H}$ NMR (Fig. S6, ESI $\dagger$ ) and SEC (Fig. S7, ESI $\dagger$ ). Chemical structure determination yielded $\mathrm{PMOXA}_{11}-b-\mathrm{PDMS}_{104}-b$ PMOXA $_{11}$ with $M_{\mathrm{n}}=9800 \mathrm{~g} \mathrm{~mol}^{-1}$ (from ${ }^{1} \mathrm{H}-\mathrm{NMR}$ ) and $D=$ 1.23 (from SEC).

${ }^{1} \mathrm{H}$ NMR $\left(500 \mathrm{MHz}, \mathrm{CDCl}_{3}\right) \delta / \mathrm{ppm}=3.84-3.15(\mathrm{bm}, 8 \mathrm{H})$, 2.30-1.96 (bm, 6H), 1.64-1.53 (bm, 4H), 1.38-1.26 (bm, 4H), $0.50-0.60(\mathrm{~m}, 4 \mathrm{H}), 0.20-0.10(\mathrm{bs}, 6 \mathrm{H})$.

\section{Synthesis and characterization of the bismaleimide linker}

To obtain the thiol-reactive linker able to covalently bind to both thiol groups of the OmpF double mutant (K89C/R270C), the disuccinimidyl-activated derivative of tartaric acid was used as diol-containing starting compound. For synthesis of the first intermediate (compound 1), an established procedure for crosslinking proteins was followed with small modifications. ${ }^{47}$ Briefly, DST (10.7 mg, $31 \mathrm{mmol}, 1.0$ eq.) was dissolved in $100 \mu \mathrm{L}$ DMSO in an Eppendorf tube $(1.5 \mathrm{~mL})$ and then a $0.24 \mathrm{M}$ aqueous solution containing L-cysteine was added (284 $\mu \mathrm{L}, 68.2 \mathrm{mmol}, 2.2$ eq.). After the $\mathrm{pH}$ was adjusted to a value between 8 and 9 with $1 \mathrm{M} \mathrm{NaOH}$ (aqueous solution), the 
reaction mixture was shaken in the dark for $16 \mathrm{~h}$ at RT. The resulting suspension was centrifuged (13.400 rpm, $5 \mathrm{~min}$ ) and the supernatant was collected. The solvent was removed using a rotary evaporator and the resulting white solid was used for the synthesis of the second intermediate (compound 2).

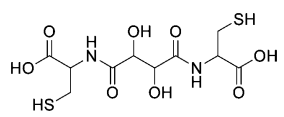

MF: $\mathrm{C}_{10} \mathrm{H}_{16} \mathrm{~N}_{2} \mathrm{O}_{8} \mathrm{~S}_{2}$, MW: 356.36, ESI-MS $\mathrm{m} / \mathrm{z}$ calculated for $\mathrm{C}_{10} \mathrm{H}_{16} \mathrm{~N}_{2} \mathrm{O}_{8} \mathrm{~S}_{2}[\mathrm{M}+2 \mathrm{H}]^{+}:$179.02; found: 179.05 .

${ }^{1} \mathrm{H}-\mathrm{NMR}\left(\mathrm{D}_{2} \mathrm{O}, 500 \mathrm{MHz}\right): \delta / \mathrm{ppm}=4.68(\mathrm{~d}), 4.65 \mathrm{ppm}(\mathrm{d})$, 3.45-3.30 (dd, $4 \mathrm{H})$.

${ }^{13} \mathrm{C}-\mathrm{NMR}\left(\mathrm{D}_{2} \mathrm{O}, 126 \mathrm{MHz}\right): \delta / \mathrm{ppm}=176.49,173.51,162.97$ (d, $J=35.5 \mathrm{~Hz}$ ), 72.45, 72.35 (d, $J=7.0 \mathrm{~Hz}), 54.87,53.49,38.72$, $37.55,25.17$.

The synthesis of compound 2 was adapted and modified from a published study. ${ }^{58} 2.8 \mathrm{mg}$ compound 1 were dissolved in $200 \mu \mathrm{L}$ of a $1 / 1$ mixture of $\mathrm{H}_{2} \mathrm{O} / \mathrm{DMF}, \mathrm{pH}>8$, and $10.7 \mathrm{mg}$ cyanine 3 maleimide $(16.0 \mathrm{mmol})$ dissolved in $400 \mu \mathrm{L}$ DMF were added. After adjusting the $\mathrm{pH}$ value back to 8 with $1 \mathrm{M} \mathrm{NaOH}$, the reaction mixture was shaken in the dark for $16 \mathrm{~h}$ at RT. The solvent was removed by adding an excess of toluene and subsequent rotary evaporation. To the crude product, $10 \mu \mathrm{L}$ $\mathrm{H}_{2} \mathrm{O}$ with a $\mathrm{pH}>8$ (adjusted with $1 \mathrm{M} \mathrm{NaOH}$ ) was added. The aqueous layer was extracted 3 times with $\mathrm{CH}_{2} \mathrm{Cl}_{2}$. The organic phases were collected, and the solvent was evaporated to give compound 2 as pink solid (7.64 $\mathrm{mg}, 4.9 \mathrm{mmol}, 61 \%$ ).

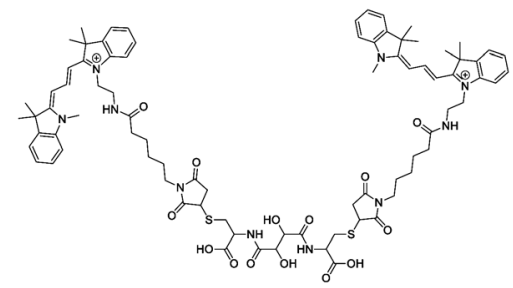

MF (cation): $\mathrm{C}_{82} \mathrm{H}_{102} \mathrm{~N}_{10} \mathrm{O}_{14} \mathrm{~S}_{2}, \mathrm{MW}: 1515.87$ (cation), ESI-MS $m / z$ calculated for $\mathrm{C}_{82} \mathrm{H}_{102} \mathrm{~N}_{10} \mathrm{O}_{14} \mathrm{~S}_{2}[\mathrm{M}+2 \mathrm{H}]^{+}$: 379.18; found: 379.16 .

${ }^{1} \mathrm{H}-\mathrm{NMR}\left(500 \mathrm{MHz}, \mathrm{CDCl}_{3}\right): \delta / \mathrm{ppm}=11.35(\mathrm{~s}, 2 \mathrm{H}), 8.38(\mathrm{t}, \mathrm{J}=$ $13.4 \mathrm{~Hz}, 2 \mathrm{H}), 7.45-7.32(\mathrm{~m}, 9 \mathrm{H}), 7.17(\mathrm{~d}, J=8.0 \mathrm{~Hz}, 2 \mathrm{H}), 7.12(\mathrm{~d}$, $J=8.0 \mathrm{~Hz}, 2 \mathrm{H}), 6.70(\mathrm{t}, J=13.9 \mathrm{~Hz}, 4 \mathrm{H}), 6.41(\mathrm{~d}, J=13.1 \mathrm{~Hz}, 2 \mathrm{H})$, $5.82(\mathrm{~d}, J=13.1 \mathrm{~Hz}, 2 \mathrm{H}), 4.17(\mathrm{t}, J=7.6 \mathrm{~Hz}, 4 \mathrm{H}), 3.69(\mathrm{~s}, 6 \mathrm{H})$, 3.52-3.39 (m, 7H), $2.30(\mathrm{t}, J=6.8 \mathrm{~Hz}, 4 \mathrm{H}), 2.23(\mathrm{~d}, J=10.4 \mathrm{~Hz}$, $8 \mathrm{H}), 1.84(\mathrm{p}, J=7.8 \mathrm{~Hz}, 4 \mathrm{H}), 1.80-1.75(\mathrm{~m}, 4 \mathrm{H}), 1.72(\mathrm{~d}, J=$ $5.5 \mathrm{~Hz}, 22 \mathrm{H}), 1.56-1.41(\mathrm{~m}, 4 \mathrm{H})$.

${ }^{13} \mathrm{C}-\mathrm{NMR}\left(126 \mathrm{MHz}, \mathrm{CDCl}_{3}\right): \delta / \mathrm{ppm}=174.73,174.57,174.04$, 171.47, 168.05, 151.03, 143.03, 142.15, 140.97, 140.69, 138.71, 129.47, 129.34, 128.15, 126.04, 125.79, 122.43, 122.40, 111.80, 111.10, 104.46, 104.18, 77.67, 77.41, 77.16, 49.61, 49.32, 44.84, 39.84, 39.47, 36.74, 31.88, 28.50, 27.47, 26.05, 25.53.

The bismaleimide linker was synthetized according to the general procedure used for chemical labelling with small

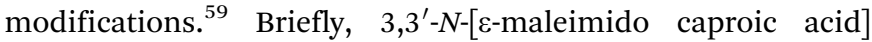

hydrazide, trifluoroacetic acid salt $(\mathrm{EMCH}, 4.2 \mathrm{mg}, 12.3 \mathrm{mmol}$, 2.5 eq.) was dissolved in $300 \mu \mathrm{L} \mathrm{H}_{2} \mathrm{O}$, and 1-ethyl-3-(3dimethylaminopropyl)-carbodiimide (EDC. $\mathrm{HCl}, 4.7 \mathrm{mg}, 24.5 \mathrm{mmol}$, 5 eq.) in $100 \mu \mathrm{L} \mathrm{H}_{2} \mathrm{O}$. A solution of compound 2 (7.6 mg, $4.9 \mathrm{mmol}$, 1 eq.) was prepared in $\mathrm{H}_{2} \mathrm{O} / \mathrm{DMF}(1: 1000,3 \mathrm{~mL})$. All three solutions were combined, and then the $\mathrm{pH}$ was adjusted to approximately 7.0 with $1 \mathrm{M} \mathrm{NaOH}$. The reaction mixture was stirred for $16 \mathrm{~h}$ in the dark at RT. The crude product was purified by extraction with dichloromethane $(\mathrm{DCM}, 3 \times)$. The organic layers were combined, and the solvent was evaporated to yield the bifunctional linker as pink solid (8.0 mg, $3.8 \mathrm{mmol}, 78 \%$ ).

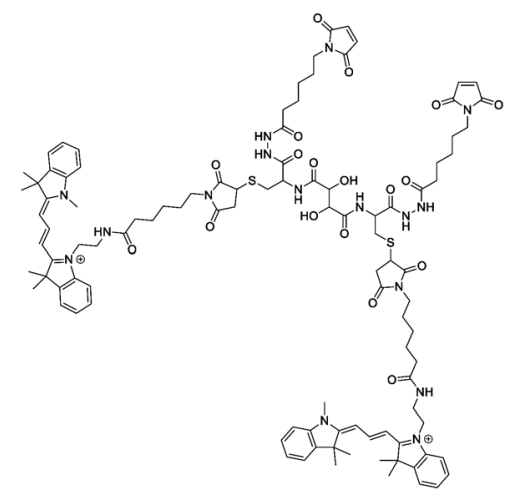

MF (cation): $\mathrm{C}_{102} \mathrm{H}_{128} \mathrm{~N}_{16} \mathrm{O}_{18} \mathrm{~S}_{2}$, MW (cation): 1930.36, ESIMS $m / z$ calculated for $\mathrm{C}_{102} \mathrm{H}_{128} \mathrm{~N}_{16} \mathrm{O}_{18} \mathrm{~S}_{2}[\mathrm{M}+\mathrm{H}]^{+}$: 643.64; found: 643.68 .

${ }^{1} \mathrm{H}-\mathrm{NMR}\left(500 \mathrm{MHz}, \mathrm{CDCl}_{3}\right): \delta / \mathrm{ppm}=7.71(\mathrm{~d}, J=16.0 \mathrm{~Hz}, 1 \mathrm{H})$, 7.58-7.49 (m, 3H), 7.46-7.30 (m, 9H), 6.87-6.67 (m, 2H), 6.46 (d, $J=16.0 \mathrm{~Hz}, 2 \mathrm{H}), 6.15(\mathrm{t}, J=1.3 \mathrm{~Hz}, 2 \mathrm{H}), 5.62-5.53(\mathrm{~m}, 1 \mathrm{H}), 5.29$ $(\mathrm{s}, 9 \mathrm{H}), 4.51-4.39(\mathrm{~m}, 6 \mathrm{H}), 4.22-3.96(\mathrm{~m}, 1 \mathrm{H}), 3.75-3.58(\mathrm{~m}, 4 \mathrm{H})$, 3.52-3.29 (m, 3H), $2.95(\mathrm{~s}, 1 \mathrm{H}), 2.88(\mathrm{~s}, 1 \mathrm{H}), 2.41-2.10(\mathrm{~m}, 4 \mathrm{H})$, 1.99-1.85 (m, 15H), 1.72 (d, $J=5.9 \mathrm{~Hz}, 16 \mathrm{H}), 1.41(\mathrm{~s}, 3 \mathrm{H}), 1.32-$ $1.17(\mathrm{~m}, 13 \mathrm{H}), 1.10(\mathrm{~s}, 8 \mathrm{H}), 0.90-0.79(\mathrm{~m}, 3 \mathrm{H}), 0.07$ (s, 1H).

${ }^{13} \mathrm{C}-\mathrm{NMR}\left(126 \mathrm{MHz}, \mathrm{CDCl}_{3}\right): \delta / \mathrm{ppm}=167.20,166.71,145.43$, 135.96, 134.29, 130.45, 128.94, 128.93, 128.16, 126.11, 117.54, $77.24,62.52,62.21,59.53,53.44,38.15,31.24,29.71,28.13$, $18.29,14.13,1.02$.

\section{Recombinant OmpF production}

Both OmpF wild type and the OmpF-M double mutant (OmpF K89C/R270C) were expressed and purified following a published procedure. ${ }^{28}$ Protein purity was evaluated on a $12 \%$ SDS-PAGE gel, and the concentration measured spectrophotometrically at $\lambda=280 \mathrm{~nm}$ with Nanodrop (Witec Ag). Wild type and mutant OmpF were stored at $4{ }^{\circ} \mathrm{C}$ in $3 \% n$-octyl- $\beta$-Dglucopyranoside (OG) at a concentration of around $3 \mathrm{mg} \mathrm{mL}$ for several months. Before use, OmpF was dialysed against $1 \mathrm{~L}$ of $0.05 \%$ OG in PBS for $16 \mathrm{~h}$, then twice against phosphate-buffered saline (PBS) for $2 \mathrm{~h}$. After the dialysis, the protein concentration was adjusted to $2.0 \mathrm{mg} \mathrm{mL} \mathrm{mith}^{-1}$ wBS.

\section{Chemical modification of OmpF-M}

OmpF-M was diluted with PBS containing 3\% OG to a concentration of $1 \mathrm{mg} \mathrm{mL} \mathrm{m}^{-1}(500 \mu \mathrm{L}, 25 \mathrm{mM}, 12.5 \mathrm{nmol})$. Next, a 
solution of the linker in MilliQ- $\mathrm{H}_{2} \mathrm{O}(7.5 \mathrm{mM})$ was added $(2.5 \mu \mathrm{L}, 19 \mathrm{nmol})$. The mixture was stirred overnight in the dark at RT. Sample and detergent concentration of the OmpF-M labeling mix was reduced by centrifuging 12 times with $1 \%$ OG in PBS through an Amicon Ultra- $0.5 \mathrm{~mL}$ centrifugal filter for protein purification and concentration, molecular cut-off $10 \mathrm{kDa}$ (Millipore). Subsequently, the volume of linker-OmpF-M suspension was adjusted to $450 \mu \mathrm{L}$ with $1 \%$ OG in PBS, transferred to a dialysis tubing with a $14 \mathrm{kDa}$ molecular cut-off (Carl Roth), and dialyzed against 1\% OG solution in PBS for $16 \mathrm{~h}$, followed by $2 \times 2 \mathrm{~h}$ dialysis against PBS. After dialysis, the protein concentration of linker-OmpF-M was measured spectrophotometrically at $\lambda=280 \mathrm{~nm}$ with Nanodrop (Witec $\mathrm{Ag}$ ) and adjusted to $2.0 \mathrm{mg} \mathrm{mL} \mathrm{m}^{-1}$.

\section{Characterization of linker-OmpF-M}

2.5-5 $\mu \mathrm{L}$ of OmpF WT, OmpF-M and linker-OmpF-M were each mixed with $4 \times$ Laemmli loading buffer $(2.5 \mu \mathrm{L})$ containing mercaptoethanol (0.7 mM). The volume was adjusted to $12.5 \mu \mathrm{L}$ with $1 \%$ OG solution and samples denatured at $95{ }^{\circ} \mathrm{C}$ for $5 \mathrm{~min}$. Samples $(10 \mu \mathrm{L})$ were loaded on a $4-20 \%$ precast polyacrylamide gel (Mini-PROTEAN ${ }^{\circledR}$ TGX $^{\mathrm{TM}}$ ) and ran at $200 \mathrm{~V}$ for $45 \mathrm{~min}$ (Fig. S5, ESI $\dagger$ ). Before Coomassie staining, the gel was imaged by Bio-Rad GelDoc to observe the fluorescence emitted by the linker (fluorescence of cyanine 3 maleimide: $\lambda_{\mathrm{ex}}=550 \mathrm{~nm} / \lambda_{\mathrm{em}}=$ $580 \mathrm{~nm})$.

\section{Preparation of laccase containing CNCs permeabilized by OmpF-M membrane insertion}

$5 \mathrm{mg} \mathrm{PMOXA}_{11}-b-\mathrm{PDMS}_{104}-b-\mathrm{PMOXA}_{11}$ triblock copolymer were dissolved in $186 \mu \mathrm{L}$ EtOH. $154 \mu \mathrm{L}$ of dialyzed OmpF (2.0 $\mathrm{mg} \mathrm{mL}^{-1}$ ) or dialyzed OG solution (3\%) as control, were added. After evaporating the solvents by a rotary evaporator (155 rpm, $40{ }^{\circ} \mathrm{C}, 175 \mathrm{mbar}$ for $10 \mathrm{~min}$, then vacuum for $15 \mathrm{~min}$ ), the polymer films were rehydrated with $1 \mathrm{~mL}$ laccase from Agaricus bisporus dissolved in PBS $\left(4.6 \mu \mathrm{g} \mathrm{mL} \mathrm{mL}^{-1}\right)$. For selfassembly of nanocompartments, the mixture was stirred overnight at RT. After extrusion (200 $\mathrm{nm}$ polycarbonate filters), CNCs were purified by size exclusion chromatography (SEC) and subsequently incubated with proteinase $\mathrm{K}\left(1 \mathrm{mg} \mathrm{mL}^{-1}\right.$, 1-2 $\mu \mathrm{L}$ per $100 \mu \mathrm{L}$ ) at $37{ }^{\circ} \mathrm{C}$ for 3 hours to remove nonencapsulated laccase.

\section{Characterization of CNCs}

The size and morphology of polymersomes were evaluated by a combination of static and dynamic light scattering (SLS, DLS), transmission electron microscopy (TEM) and fluorescence correlation spectroscopy (FCS). Quantification of reconstituted linker-OmpF-M was carried out by FCS measurements. All three techniques revealed a vesicular, hollow sphere structure of the CNCs with a size of around $200 \mathrm{~nm}$. Additionally, we calculated the value for $R_{\mathrm{h}}$ based on the diffusion times of BODIPY stained vesicles measured by FCS (Table S1, ESI $\dagger$ ). With a diffusion time of around $6000 \mu \mathrm{s}$, we received an $R_{\mathrm{h}}$ of $92.1 \mathrm{~nm}$, resulting in a polymersome diameter of $184.2 \mathrm{~nm}$, which is in agreement with the dimensions obtained by TEM and LS (Fig. 2).
Cryo-TEM images of vesicles formed by $\mathrm{PMOXA}_{11}-b-\mathrm{PDMS}_{104}-b$ $\mathrm{PMOXA}_{11}$ revealed a membrane thickness of around $15 \mathrm{~nm}$ (Fig. S10, ESI $\dagger$ ). To exclude unspecific binding of linker-OmpF$\mathrm{M}$ to the CNC membrane, FCS measurements were performed with linker-OmpF-M added to preformed CNC-noOmpF (Fig. S11 and Table S1, ESI $\dagger$ ). Although FCS measurements revealed an increased diffusion time compared to the free linker, the shift of fitted autocorrelation curves was less pronounced than that observed for linker-OmpF-M reconstituted into CNCs. In addition, to confirm that the detergent (1\% OG) used to solubilize linker-OmpF-M did not disrupt CNCs, we added hydrophobic BODIPY 630/650-X to stain the nanocompartment membrane and measure the vesicle diffusion time by FCS.

\section{DLS/SLS}

Light scattering experiments were performed using an ALV goniometer (ALV GmbH, Germany) equipped with an ALV He-Ne laser (JDS Uniphase, wavelength $\lambda=632.8 \mathrm{~nm}$ ). Following film rehydration, samples $(10 \mu \mathrm{L}$ of self-assembled nanocompartments added to $990 \mu \mathrm{L}$ PBS) were measured in a $10 \mathrm{~mm}$ cylindrical quartz cell at angles ranging from $35^{\circ}$ to $135^{\circ}$ at $293 \mathrm{~K}$ with angular steps of $5^{\circ}$. ALV/static and dynamic FIT and PLOT program version 4.31 10/10 were used for data analysis. Static light scattering (SLS) data were processed according to the MIE and Guinier plotting models.

\section{TEM}

Nanocompartment solutions were diluted in a ratio of $1: 3$ with PBS. $5 \mu \mathrm{L}$ aliquots were deposited on a carbon-coated copper grid and negatively stained with $2 \%$ uranyl acetate solution. The samples were examined with a transmission electron microscope (Philips CM-100) operated at $80 \mathrm{kV}$.

\section{Cryo-TEM}

Aliquots of the samples $(4 \mu \mathrm{L})$ were deposited on a holey carbon-coated grid (Lacey, Tedpella, USA), and vitrified into liquid ethane at $-178{ }^{\circ} \mathrm{C}$ using a Leica GP plunger (Leica, Austria). The frozen samples were examined with a Talos electron microscope (FEI, USA) operated at $200 \mathrm{kV}$.

\section{NTA}

Nanoparticle tracking analyses (NTA) were performed using a NanoSight NS3000 equipped with a blue $(488 \mathrm{~nm})$ and green laser $(532 \mathrm{~nm})$. The samples were diluted at 1:1000 in PBS to avoid concentration-related interference. The CNCs were excited with the blue laser and their emission was detected by using appropriate filters. The average particle concentration was calculated using the Stokes-Einstein equation for spherical particle suspensions. The hydrodynamic radius distribution was analysed by NanoSight's single particle tracking system.

\section{FCS}

All FCS measurements were carried out using a confocal laser scanning microscope (ZEISS LSM 880, Carl Zeiss, Germany) equipped with a water immersion objective (C-Apochromate $40 \times / 1.2$ W korr FCS M27) using the Zen Black software. A HeNe 
laser (561 nm or $633 \mathrm{~nm}$ ) was used to excite the samples. The measurements were carried out at room temperature using a sample volume of $20 \mu \mathrm{L}$. Measurements were recorded over $10 \mathrm{~s}$, and each measurement was repeated 30 times. The diffusion times of the free dye (100 $\mathrm{nM}$ cyanine 3 maleimide), the linker and the different types of CNCs were measured independently. The autocorrelation function was calculated using a software correlator and fitted with a one component fit. Less than $10 \%$ of the correlation curves could not be fitted and were excluded from the analysis.

\section{Enzyme encapsulation efficiency}

To assess laccase encapsulation efficiency, we first determined the initial concentration of the laccase (MW: $65000 \mathrm{~g} \mathrm{~mol}^{-1},{ }^{60}$ confirmed by SDS PAGE, Fig. S12, ESI $\dagger)$ in solution $\left(4.60 \mu \mathrm{g} \mathrm{mL}^{-1}\right)$ by BCA according to the supplier's protocol (Thermo Fisher Scientific, USA, Fig. S12, ESI $\dagger$ ) and subsequently the concentration of the non-encapsulated in the eluate from SEC purification of CNC-noOmpF. The difference between the amount of laccase added for the formation of the CNCs and the amount of enzyme that was not encapsulated $(3.70 \mu \mathrm{g})$, corresponded to the amount of laccase encapsulated in our CNCs-noOmpF. Dividing the total number of encapsulated laccase molecules by the number of vesicles (total volume $0.85 \mathrm{~mL}, 2.6 \times 10^{11} \pm 1.6 \times 10^{10}$ vesicles per mL, measured by NTA; see Table S2, ESI $\dagger$ ) yielded a value of 8-9 encapsulated laccase molecules per vesicle.

\section{Opening of linker-OmpF-M}

$\mathrm{NaIO}_{4}$ dissolved in MilliQ- $\mathrm{H}_{2} \mathrm{O}(0.3 \mathrm{M}, 10 \mu \mathrm{L}, 1$ eq.) was added to $100 \mu \mathrm{L}$ of $\mathrm{CNCs}$ and incubated at $37{ }^{\circ} \mathrm{C}$. Assuming approximately $2 \times 10^{10} \mathrm{CNCs}$ in the periodate/CNC mixture $(110 \mu \mathrm{L})$, we calculated $1.6 \times 10^{-7} \mathrm{mmol}$ or $3.5 \times 10^{-5} \mathrm{mg}$ periodate per vesicle. After $24 \mathrm{~h}$, an excess of glucose dihydrate dissolved in MilliQ- $\mathrm{H}_{2} \mathrm{O}\left(0.6 \mathrm{M}, 25 \mu \mathrm{L}, 5\right.$ eq.) was added to quench $\mathrm{NaIO}_{4}$, and incubation at $37{ }^{\circ} \mathrm{C}$ was continued for $24 \mathrm{~h}$. Subsequently, CNCs were purified by SEC and incubated with proteinase $\mathrm{K}$ ( $1 \mathrm{mg} \mathrm{mL}^{-1}, 2 \mu \mathrm{L}$ per $100 \mu \mathrm{L} \mathrm{CNCs}$ ) to remove residual laccase attached to the outer surface of CNCs.

\section{Enzymatic assay with DMP}

Aliquots of free laccase ( $1 \mathrm{pg}$ in $5 \mu \mathrm{L}$, corresponding to the amount of laccase in $\left.1 \times 10^{9} \mathrm{CNCs}\right)$, CNCs without $\mathrm{NaIO}_{4}$ treatment $(5 \mu \mathrm{L})$, and CNCs incubated with $\mathrm{NaIO}_{4}$ and glucose (20 $\mu \mathrm{L}$, accounting for the dilution after SEC purification of treated CNCs) were added to 2,6-dimethoxyphenol (DMP) in PBS $(20 \mathrm{mM}, 10 \mu \mathrm{L})$ at $\mathrm{pH} 7.4$ and adjusted to a final volume of $210 \mu \mathrm{L}$ per well with PBS in a 96-well plate. The absorbance at $470 \mathrm{~nm}$ was measured with a Spectramax M5e microplate reader (Molecular Devices). The concentration of all CNC samples in PBS was determined by NTA (Table S2, ESI $\dagger$ ) to perform the assays at comparable enzyme concentrations.

\section{Enzymatic assay with ABTS}

Corresponding laccase activity measurements were carried out using 2,2'-azinobis[3-ethylbenzothiazoline-6-sulfonic acid]diammonium salt (ABTS) as substrate. The oxidation product was monitored by determining the increase of absorbance at $420 \mathrm{~nm}$ using a Spectramax M5e microplate reader (Molecular Devices).

\section{Conclusions}

By means of a specifically designed, periodate sensitive linker we achieved exquisite spatiotemporal control of catalysis in polymeric nanosized compartments with OmpF channels inserted in their membranes. Covalent coupling of the linker to OmpF pores efficiently blocked the entry of substrates to the compartment, preventing the catalytic activity of the enzyme confined inside. We have previously reported a related strategy to control OmpF pore function via a molecular cap that is cleaved off in response to reductive agents, leading to the opening of $\mathrm{OmpF},{ }^{30}$ whereas here, we developed a complementary approach based on a linker with an entirely different chemistry. Periodate-induced linker cleavage opened the 'locks' for the passage of substrates and catalysis occurred. Importantly, the catalytic reactions are induced under mild conditions (no organic solvents, at pH 7, RT) where sensitive biomolecules remain intact. Moreover, the periodate cleavage of the linker did not affect the overall CNC structure, ensuring the full functionality of our system. Another attractive feature of this well controllable system is that the catalytic activity is preserved over months. Our means of switching on confined catalysis pave the way to new molecular technology approaches which might be extremely useful in multifunctional cluster activity when specific substrates or products need to be made available at a specific site and with precise timing to a downstream catalyst. We believe that our linker-based, periodate responsive OmpF modification conferring controllable functionality and improved properties upon CNCs could advance the development of sensitive catalysts based on CNCs for a broad range of applications including catalysis, food science and nanotechnology.

\section{Author contributions}

Conceptualization: L. Zartner, C. G. Palivan, formal analysis: L. Zartner, V. Maffeis, I. A. Dinu, investigation: L. Zartner, V. Maffeis, methodology: L. Zartner, supervision: C.-A. Schoenenberger, C. P. Palivan, validation: L. Zartner, visualization: L. Zartner, V. Maffeis, C.-A. Schoenenberger, writing - original draft: L. Zartner, V. Maffeis, C. A. Schoenenberger, writing - review \& editing: I. A. Dinu, C.-A. Schoenenberger, C. G. Palivan.

\section{Conflicts of interest}

There are no conflicts to declare.

\section{Acknowledgements}

We gratefully acknowledge the financial support provided by the Swiss National Science Foundation (SNSF), the National 
Centre of Competence in Research Molecular Systems Engineering, and the University of Basel. Authors thank Prof. Dr Timm Maier (Biozentrum, University of Basel, Switzerland) for his advice on the linker design and Dr Voichita Mihali (Department of Chemistry, University of Basel, Switzerland) for TEM micrographs.

\section{Notes and references}

1 T. M. Reineke, ACS Macro Lett., 2016, 5, 14-18.

2 A. Abdollahi, H. Roghani-Mamaqani, B. Razavi and M. Salami-Kalajahi, Polym. Chem., 2019, 10, 5686-5720.

3 C. E. Ashley, E. C. Carnes, G. K. Phillips, D. Padilla, P. N. Durfee, P. A. Brown, T. N. Hanna, J. Liu, B. Phillips, M. B. Carter, N. J. Carroll, X. Jiang, D. R. Dunphy, C. L. Willman, D. N. Petsev, D. G. Evans, A. N. Parikh, B. Chackerian, W. Wharton, D. S. Peabody and C. J. Brinker, Nat. Mater., 2011, 10, 389-397.

4 T. Anajafi and S. Mallik, Ther. Delivery, 2015, 6, 521-534.

5 J. Leong, J. Y. Teo, V. K. Aakalu, Y. Y. Yang and H. Kong, Adv. Healthcare Mater., 2018, 7, 1701276.

6 K. T. Kim, J. J. L. M. Cornelissen, R. J. M. Nolte and J. C. M. van Hest, Adv. Mater., 2009, 21, 2787-2791.

7 M. Lomora, G. Gunkel-Grabole, S. Mantri and C. G. Palivan, Chem. Commun., 2017, 53, 10148-10151.

8 C.-Y. Xing, Y.-C. Fan, X. Chen, J.-S. Guo, Y. Shen, P. Yan, F. Fang and Y.-P. Chen, Sci. Total Environ., 2020, 717, 137030.

9 J. Song, W. He, H. Shen, Z. Zhou, M. Li, P. Su and Y. Yang, Chem. Eng. J., 2020, 390, 124488.

10 K. T. Kim, J. J. L. M. Cornelissen, R. J. M. Nolte and J. C. M. van Hest, J. Am. Chem. Soc., 2009, 131, 13908-13909.

11 J. F. Mukerabigwi, Z. Ge and K. Kataoka, Chem. - Eur. J., 2018, 24, 15706-15724.

12 F. Eisenreich, E. W. Meijer and A. R. A. Palmans, Chem. Eur. J., 2020, 26, 10355-10361.

13 I. J. Minten, V. I. Claessen, K. Blank, A. E. Rowan, R. J. M. Nolte and J. J. L. M. Cornelissen, Chem. Sci., 2011, 2, 358-362.

14 S. Yu, T. Azzam, I. Rouiller and A. Eisenberg, J. Am. Chem. Soc., 2009, 131, 10557-10566.

15 L. Xu, N. Ren, J. Pang, H. Deng, X. Zhu, M. Sun and D. Yan, Polym. Chem., 2017, 8, 6283-6288.

16 Q. Yan, J. Wang, Y. Yin and J. Yuan, Angew. Chem., Int. Ed., 2013, 52, 5070-5073.

17 H. Xu, F. Meng and Z. Zhong, J. Mater. Chem., 2009, 19, 4183-4190.

18 F. Liu, V. Kozlovskaya, S. Medipelli, B. Xue, F. Ahmad, M. Saeed, D. Cropek and E. Kharlampieva, Chem. Mater., 2015, 27, 7945-7956.

19 B. Iyisan, J. Kluge, P. Formanek, B. Voit and D. Appelhans, Chem. Mater., 2016, 28, 1513-1525.

20 J. Qin, Q. Liu, J. Zhang, J. Chen, S. Chen, Y. Zhao and J. Du, ACS Appl. Mater. Interfaces, 2015, 7, 14043-14052.
21 H. C. Chiu, Y. W. Lin, Y. F. Huang, C. K. Chuang and C. S. Chern, Angew. Chem., Int. Ed., 2008, 47, 1875-1878.

22 J. Gaitzsch, D. Appelhans, L. Wang, G. Battaglia and B. Voit, Angew. Chem., Int. Ed., 2012, 51, 4448-4451.

23 M. Garni, S. Thamboo, C.-A. Schoenenberger and C. G. Palivan, Biochim. Biophys. Acta, Biomembr., 2017, 1859, 619-638.

24 S. Lee, N. G. Housden, S. A. Ionescu, M. H. Zimmer, R. Kaminska, C. Kleanthous and H. Bayley, J. Am. Chem. Soc., 2020, 142, 12157-12166.

25 A. Belluati, I. Craciun, J. Liu and C. G. Palivan, Biomacromolecules, 2018, 19, 4023-4033.

26 M. Lomora, M. Garni, F. Itel, P. Tanner, M. Spulber and C. G. Palivan, Biomaterials, 2015, 53, 406-414.

27 O. Onaca, P. Sarkar, D. Roccatano, T. Friedrich, B. Hauer, M. Grzelakowski, A. Güven, M. Fioroni and U. Schwaneberg, Angew. Chem., Int. Ed., 2008, 47, 7029-7031.

28 C. Edlinger, T. Einfalt, M. Spulber, A. Car, W. Meier and C. G. Palivan, Nano Lett., 2017, 17, 5790-5798.

29 T. Einfalt, D. Witzigmann, C. Edlinger, S. Sieber, R. Goers, A. Najer, M. Spulber, O. Onaca-Fischer, J. Huwyler and C. G. Palivan, Nat. Commun., 2018, 9, 1127.

30 E. Yamashita, M. V. Zhalnina, S. D. Zakharov, O. Sharma and W. A. Cramer, EMBO J., 2008, 27, 2171-2180.

31 K. A. Kristiansen, A. Potthast and B. E. Christensen, Carbohydr. Res., 2010, 345, 1264-1271.

32 A. S. Perlin, in Advances in Carbohydrate Chemistry and Biochemistry, ed. D. Horton, Academic Press, 2006, vol. 60, pp. 183-250.

33 A. Sudalai, A. Khenkin and R. Neumann, Org. Biomol. Chem., 2015, 13, 4374-4394.

34 W. Wang, L. Lu, K.-J. Wu, J. Liu, C.-H. Leung, C.-Y. Wong and D.-L. Ma, Sens. Actuators, B, 2019, 288, 392-398.

35 S. Sakamoto, G. Yusakul, Y. Tsuneura, W. Putalun, K. Usui, T. Miyamoto, H. Tanaka and S. Morimoto, Analyst, 2017, 142, 1140-1148.

36 N. K. Dunlap, W. Mergo, J. M. Jones and J. D. Carrick, Tetrahedron Lett., 2002, 43, 3923-3925.

37 Y. Yang, H. Hahne, B. Kuster and S. H. Verhelst, Mol. Cell. Proteomics, 2013, 12, 237-244.

38 A. Maurer, C. Zeyher, B. Amin and H. Kalbacher, J. Proteome Res., 2013, 12, 199-207.

39 E. Nyfeler, J. Grognux, D. Wahler and J.-L. Reymond, Helv. Chim. Acta, 2003, 86, 2919-2927.

40 Q. Zhu, M. Uttamchandani, D. Li, M. L. Lesaicherre and S. Q. Yao, Org. Lett., 2003, 5, 1257-1260.

41 K. L. Larsen, R. J. Andersen and J. Brask, Enzyme Microb. Technol., 2016, 91, 66-71.

42 Y. Yang and S. H. L. Verhelst, Chem. Commun., 2013, 49, 5366-5368.

43 B. Sklarz, Q. Rev., Chem. Soc., 1967, 21, 3-28.

44 D. Y. Shroder, L. G. Lippert and Y. E. Goldman, Methods Appl. Fluoresc., 2016, 4, 042004.

45 S. Tyagi and E. A. Lemke, in Methods in Cell Biology, ed. P. M. Conn, Academic Press, 2013, vol. 113, pp. 169-187.

46 T. E. Gartner and A. Jayaraman, Macromolecules, 2019, 52, 755-786. 
47 N. Geisler, FEBS Lett., 1993, 323, 63-67.

48 X. Wang, D. Teng, Q. Guan, R. Mao, Y. Hao, X. Wang, J. Yao and J. Wang, AMB Express, 2017, 7, 155.

49 D. Wu, S. Rigo, S. Di Leone, A. Belluati, E. C. Constable, C. E. Housecroft and C. G. Palivan, Nanoscale, 2020, 12, 1551-1562.

50 F. Itel, A. Najer, C. G. Palivan and W. Meier, Nano Lett., 2015, 15, 3871-3878.

51 S. T. Poschenrieder, S. K. Schiebel and K. Castiglione, Eng. Life Sci., 2017, 18, 101-113.

52 E. Breslmayr, M. Hanžek, A. Hanrahan, C. Leitner, R. Kittl, B. Šantek, C. Oostenbrink and R. Ludwig, Biotechnol. Biofuels, 2018, 11, 79.

53 C. Draghici, V. Mikhalevich, G. Gunkel-Grabole, J. Kowal, W. Meier and C. G. Palivan, Langmuir, 2018, 34, 9015-9024.
54 A. Moquin, J. Ji, K. Neibert, F. M. Winnik and D. Maysinger, ACS Omega, 2018, 3, 13882-13893.

55 L. I. Ramírez-Cavazos, C. Junghanns, N. Ornelas-Soto, D. L. Cárdenas-Chávez, C. Hernández-Luna, P. Demarche, E. Enaud, R. García-Morales, S. N. Agathos and R. Parra, J. Mol. Catal. B: Enzym., 2014, 108, 32-42.

56 P. Baumann, M. Spulber, I. A. Dinu and C. G. Palivan, J. Phys. Chem. B, 2014, 118, 9361-9370.

57 F. Itel, M. Chami, A. Najer, S. Lörcher, D. Wu, I. A. Dinu and W. Meier, Macromolecules, 2014, 47, 7588-7596.

58 C. W. Scales, A. J. Convertine and C. L. McCormick, Biomacromolecules, 2006, 7, 1389-1392.

59 C.-C. Lin and K. S. Anseth, Adv. Funct. Mater., 2009, 19, 2325-2331.

60 C. R. Perry, S. E. Matcham, D. A. Wood and C. F. Thurston, J. Gen. Microbiol., 1993, 139, 171-178. 